\title{
O PENSAMENTO DE CHARLES DARWIN (1809-1882) NO ESTUDO DOS JOGOS COOPERATIVOS
}

Joaquim Francisco Lira Neto, Colégio Militar de Manaus - CMM, Manaus, Amazonas Brasil

\section{RESUMO \\ O presente trabalho busca explicitar as formas sociais de competição e cooperação defendidas por Charles Darwin (1809-1882), para que seja retomada a interpretação do pensamento do autor feita por alguns dos mais conceituados estudiosos dos Jogos Cooperativos. Tais estudiosos defendem que, para Darwin, a cooperação seria um valor mais importante para a sociedade do que a competição; entretanto, a análise de suas principais obras revela a legitimação das piores formas de competição social, ligadas à dominação do homem pelo homem, que o autor tenta justificar pela inelutável lei da seleção natural. \\ Palavras-Chave: Evolução; Seleção natural; Jogos em grupo. \\ THE CHARLES DARWIN'S (1809-1882) THOUGHT IN THE STUDY OF COOPERATIVE GAMES}

\begin{abstract}
This work seeks to clarify the social ways of competition and cooperation advocated by Charles Darwin (1809-1882), to make a resumption of the interpretation of the author's thought by some of the most authoritative scholars of the Cooperative Games. These scholars argue that, to Darwin, cooperation would be a more important value to society than the competition; however, the analysis of his main works reveals the legitimation of the worst forms of social competition, linked to the domination of man by man, that the author tries to justify by the inevitable law of natural selection.

Key-Words: Evolution; Natural selection; Group games.
\end{abstract}

\section{EL PENSAMIENTO DE CHARLES DARWIN (1809-1882) EN EL ESTUDIO DE LOS JUEGOS COOPERATIVOS}

\footnotetext{
RESUMEN

Este trabajo tiene por objeto aclarar las formas sociales de la competencia y la cooperación promovidas por Charles Darwin (1809-1882), para una reanudación de la interpretación del pensamiento del autor por algunos de los eruditos más respetados de Juegos Cooperativos. 
Estos estudiosos sostienen que, a Darwin, la cooperación sería un valor más importante para la sociedad que la competencia; sin embargo, el análisis de sus principales obras revela la legitimación de las peores formas de competencia social, vinculadas a la dominación del hombre por el hombre, que el autor trata de justificar por la inevitable ley de la selección natural.

Palabras-Clave: Evolución; Selección natural; Juegos de grupo. 


\section{INTRODUÇÃO}

A leitura de alguns dos clássicos da área dos Jogos Cooperativos nos traz - como será tratado mais adiante - uma visão do pensamento de Charles Darwin (1809-1882) segundo a qual a cooperação é um valor mais importante para a humanidade, em termos de sobrevivência, do que a competição. Embora haja passagens em obras do renomado evolucionista que sustentem tal afirmação, há também a defesa das piores formas de competição social, o que torna a questão polêmica, de tal modo que se propõe aqui uma releitura de tal visão, que é de grande relevância e complexidade.

Para a consecução do referido objetivo será feita uma breve análise do contexto em que Darwin desenvolveu sua teoria. Tal análise levará em consideração não somente as relações de produção da economia vigentes na época, mas também as elaborações intelectuais que buscavam a legitimação destas relações de produção, e que constituem fontes das quais Darwin partiu para a sistematização de sua teoria evolucionista.

\section{DARWIN NO ESTUDO DOS JOGOS COOPERATIVOS}

O estudo dos Jogos Cooperativos, que hoje já está bastante difundido no Brasil, tendo produzido um número significativo de publicações que buscam analisar diferentes aspectos de seu objeto, tem como um de seus principais precursores o professor e pesquisador canadense Terry Orlick.

Em seu livro Vencendo a competição, o autor faz uma crítica aos valores individualistas hegemônicos, perceptíveis através de determinados comportamentos competitivos, agressivos, ou que mostram pessoas que sofrem com a desigualdade social. É importante lembrar que Orlick $^{1}$ não deixa de distinguir formas de competição propriamente destrutivas, desumanizadoras, de formas de competição que não acarretam, necessariamente, em subjugação, aviltamento.

A questão relevante para o presente trabalho é que, para fundamentar a tese de que as formas perniciosas de competição são geradas pela estrutura social, e não por um impulso inato 
irrefreável, Orlick ${ }^{1}$ tem como referência, entre outros autores, a antropóloga Margaret Mead, o filósofo Erich Fromm, e Charles Darwin.

No que se refere a Darwin, e a sua famosa teoria da seleção natural ou sobrevivência do mais apto, Orlick ${ }^{1}$ defende que há equívocos na interpretação tradicionalmente feita do darwinismo, a qual poderia usá-lo para legitimar formas de dominação. $\mathrm{O}$ autor ${ }^{1: 21}$ afirma que:

O conceito de sobrevivência do mais apto tem sido usado com abuso para justificar o princípio de que "a força está certa". Entretanto, "o mais apto" não justifica ser o mais forte ou o mais bruto. Darwin ficou amargurado por suas teorias terem sido distorcidas para justificar negociatas, crueldades e guerras contra os mais fracos. Essas teorias da seleção natural foram mal interpretadas e deturpadas para justificar a exploração dos pobres pelos ricos. Negociantes ambiciosos, políticos fraudulentos e cidadãos desonestos racionalizaram seus próprios comportamentos desumanos apoiando-se na sobrevivência do mais apto. Ajudaram a perpetuar o mito da vitória-aqualquer custo e a ideia de que os "perdedores" merecem ser esmagados. Entretanto, apesar do mau uso de suas teorias, Charles Darwin afirmou claramente que, para a raça humana, o valor mais alto de sobrevivência está na inteligência, no senso moral e na cooperação social - e não na competição.

A importância da obra de Orlick para o estudo dos Jogos Cooperativos pode ser percebida pelas referências a ele feitas por diversos autores que se dedicam a esta temática. Entre eles estão Brotto, ${ }^{2-3}$ Brown $^{4}$ e Soler. ${ }^{5-6}$ Estes autores, que, por sua vez, também são importantes referências na área de estudo em questão, foram aqui lembrados porque trouxeram para as suas obras parte do trecho supracitado escrito por Orlick. ${ }^{1}$

Os leitores que entram em contato com qualquer um destes trabalhos sobre os Jogos Cooperativos - seja através de Orlick ou, indiretamente, através dos demais autores - se deparam com uma interpretação segundo a qual Darwin defenderia, principalmente, formas sociais de cooperação, injustificando-se, portanto, o emprego do darwinismo na legitimação de formas de competição ligadas à promoção de desigualdades, à dominação.

Em seguida será feita uma breve caracterização do contexto social em que Darwin desenvolveu a sua teoria evolucionista. Serão consideradas tanto as relações de produção da economia vigentes na época, como as elaborações intelectuais que buscavam a legitimação destas relações de produção. Esta breve caracterização tem como objetivo explicitar aspectos 
do darwinismo que escapam à interpretação feita pelos autores acima citados que estudam os Jogos Cooperativos.

\section{DARWIN EM SEU CONTEXTO HISTÓRICO}

Charles Darwin (1809-1882) entrou para a História pela sua contribuição à teoria evolucionista, que representou um choque para a época, principalmente, por conflitar com determinadas concepções religiosas. Basicamente, o evolucionismo negava que Deus tinha criado todos os seres vivos e que, entre estes, o homem tinha um lugar privilegiado por ter sido criado à imagem e semelhança do criador. Para Darwin, o homem é o resultado de uma cadeia evolutiva e busca garantir sua sobrevivência através de muitos dos mesmos processos utilizados por todos os demais seres vivos.

É fundamental para o entendimento do darwinismo a sua contextualização, pois suas ideias fundamentais, que partem de outros teóricos da época, atendem claramente às necessidades históricas geradas pelas contradições materiais nas quais se encontrava a Grã-Bretanha, uma das maiores potências capitalistas do século XIX.

Como lembra Hobsbawm, ${ }^{7}$ tendo feito sua revolução já no século XVII, que derrubou o poder dos monarcas hereditários e privilegiou o desenvolvimento econômico através das trocas mercantis e do lucro privado, a Grã-Bretanha atingiu, no século XVIII, a partir da década de 1780, um grande avanço no desenvolvimento de suas forças produtivas materiais, que ficou conhecido como Revolução Industrial.

Para Hobsbawm, houve uma dupla revolução, na qual, ao lado da política e ideologia fornecidas ao mundo pela Revolução Francesa, estava a economia formada pela Revolução Industrial, que proporcionou uma "multiplicação rápida, constante, e, até o presente, ilimitada, de homens, mercadorias e serviços". 7:44

Tanto a burguesia britânica como a francesa queriam a ruptura dos laços estanques de hereditariedade e religiosidade que imperavam no Antigo Regime; as condições materiais para

Conexões: revista da Faculdade de Educação Física da UNICAMP, Campinas, v. 13, n. 3, p. 131-145, jul./set. 2015. ISSN: 1983-9030 
isto já estavam dadas, ou seja, a industrialização significou um aumento nas forças produtivas de modo a exigir novas relações de produção, para além das limitações do interior dos feudos.

O burguês precisava expandir os horizontes das trocas de mercadorias e precisava de uma sociedade estratificada pelo desempenho obtido nestas trocas, em que ele adquirisse benefícios atribuídos ao seu mérito individual; precisava de uma carreira aberta ao talento. Os interesses da burguesia foram expostos na Declaração dos Direitos do Homem e do Cidadão, de 1789. Analisando o texto da Declaração, Hobsbawm ${ }^{7: 77}$ afirma:

Este documento é um manifesto contra a sociedade hierárquica de privilégios nobres, mas não um manifesto a favor de uma sociedade democrática e igualitária. "Os homens nascem e vivem livres e iguais perante as leis", dizia seu primeiro artigo; mas ela também prevê a existência de distinções sociais, ainda que "somente no terreno da utilidade comum". A propriedade privada era um direito natural, sagrado, inalienável e inviolável. Os homens eram iguais perante a lei e as profissões estavam igualmente abertas ao talento; mas, se a corrida começasse sem handicaps, era igualmente entendido como fato consumado que os corredores não terminariam juntos.

Ao romper com a aristocracia feudal, a burguesia conseguiu implantar um novo regime, baseado no carreirismo individual e na livre-concorrência, marcas essenciais do liberalismo. Neste contexto, dois teóricos que forneceram elementos para o darwinismo ocupam lugar de destaque: Thomas Robert Malthus (1766-1834) e Herbert Spencer (1820-1903).

O economista inglês Thomas R. Malthus ficou famoso por afirmar que a população possui uma tendência para, se não for controlada, aumentar em progressão geométrica, enquanto que a produção de alimentos apenas consegue crescer em progressão aritmética. Considerando que a comida e a paixão entre os sexos são necessários à preservação da existência, a miséria é, para Malthus, uma lei fixa da natureza humana. Para ele: "prevenir a ocorrência da miséria acha-se, infelizmente, fora do alcance do poder humano". ${ }^{8: 50}$

Como a população tende a crescer de modo a ultrapassar os limites dos meios de subsistência, a miséria cumpriria a importante função de controlar o excedente populacional. Desta forma, para Malthus, ${ }^{8}$ a miséria tem uma causa natural, não sendo devida à propriedade privada dos meios de produção da economia, ao Estado e às instituições, que, para o autor, visam amenizar os efeitos deste mal necessário.

Conexões: revista da Faculdade de Educação Física da UNICAMP, Campinas, v. 13, n. 3, p. 131-145, jul./set. 2015. ISSN: 1983-9030 
A necessidade atuaria para forçar os humanos, principalmente os mais pobres, a trabalharem mais e a terem menos filhos, selecionando os indivíduos mais talentosos. Malthus afirma: "as dificuldades da vida contribuem para gerar talentos, a experiência quotidiana basta para nos convencer". 8:134 O problema desta afirmação é o sentido que possui no texto de Malthus. O ilustre economista se opõe à Lei dos Pobres inglesa, destinada a fornecer auxílio aos mais necessitados, porque, para ele, ela estimula os pobres menos laboriosos a terem mais filhos.

Os indivíduos deveriam se esforçar "até ao limite de suas possibilidades" ":68 e mesmo medidas simples como a Lei dos Pobres, por parte do Estado, destruiriam os "verdadeiros princípios da liberdade e igualdade". 8:68 Não se trata de, no presente trabalho, defender a saída assistencialista da qual a burguesia lança mão; trata-se, outrossim, de explicitar o absurdo nível de livre-competição defendida por Malthus em sua teoria.

Darwin, no seu clássico A origem das espécies, afirma que a luta pela existência ocorre, inevitavelmente, entre todos os seres do mundo devido "à alta razão geométrica do seu crescimento". 9:47 E complementa: "Esta é a doutrina de Malthus, aplicada aos reinos animal e vegetal". 9:47

Assim como Malthus, o filósofo e sociólogo positivista inglês Herbert Spencer foi grande fonte da qual Darwin partiu para elaborar sua teoria evolucionista. Spencer, inclusive, foi quem cunhou a famosa expressão sobrevivência do mais apto, muito utilizada por Darwin.

Para Spencer, ${ }^{10}$ há uma lei universal segundo a qual todo o progresso, quer se trate de transformações da Terra ou do desenvolvimento das instituições políticas, ocorre com a evolução do simples para o complexo, do homogêneo para o heterogêneo, através de sucessivas diferenciações. Na análise do autor, a inteligência, que evolui da criança para o adulto, assim como a cultura, que evolui do selvagem para o homem civilizado, são exemplos de progressos.

As tribos consideradas por Spencer como primitivas, bárbaras, são, para ele, um "agregado homogêneo de indivíduos que têm o mesmo poder e exercem idênticas funções". 10:28 Nelas, todos os homens exercem as mesmas atividades, como as de guerreiros, pescadores ou 
fabricantes de utensílios. Para o sociólogo em questão, com a evolução da estrutura social "vai aumentando o contraste entre o governante e os governados"; 10:29 além disso, surgem progressos como a "extraordinária divisão do trabalho que caracteriza as nações adiantadas". 10:32

Spencer desenvolve uma visão evolucionista, afirmando que, no decurso de muitas gerações, ocorrem muitas variações que se adaptam, mais ou menos, às novas condições. Há, para o autor, além da tendência de cada raça de organismos para se diferenciar em outras raças, a "tendência para a produção ocasional de organismos superiores". 10:76 Para ele, o "homem civilizado separa-se muito mais do arquétipo do seu grupo que o selvagem", ${ }^{10: 78}$ o que significaria a superioridade do primeiro em relação ao último.

Como exposto acima, o autor defende a divisão social do trabalho, através da qual cada indivíduo se dedicaria, preferencialmente, apenas a um determinado ramo de atividade, que seria aquele para o qual demonstrasse aptidão. Esta divisão não se limitaria a uma nação, devendo ser estendida aos mais diversos países. Para Spencer, "a troca de produtos, que o livre-câmbio promete aumentar de modo tão considerável, terá como resultado especializar, em maior ou menor grau, a indústria de cada povo". 10:33

Em sua defesa da livre-concorrência, afirma ainda que "rivalizando entre si, os produtores procuram oferecer melhores artigos, o que os leva a descobrir processos aperfeiçoados ou mais excelentes matérias-primas", ${ }^{10: 82}$ buscando, desta forma, legitimar as relações de produção burguesas e a prática colonialista britânica, através do discurso do progresso, da civilização, do domínio dos mais aptos.

$\operatorname{Darwin}^{9: 66}$ refere-se a Spencer na passagem em que descreve o mecanismo da seleção natural ou sobrevivência do mais apto, da seguinte maneira:

Devido à luta pela vida, as variações, quando são de algum modo benéficas ao indivíduo de uma espécie, nas suas relações infinitamente complexas com os outros seres orgânicos e com suas condições físicas de vida, tenderão a preservar esses indivíduos e geralmente são herdadas pela sua prole. Os descendentes terão assim maior probabilidade de sobreviver, pois entre os muitos indivíduos nascidos, de qualquer espécie, apenas um pequeno número sobrevive. Denominei este princípio pelo qual cada pequena variação,

Conexões: revista da Faculdade de Educação Física da UNICAMP, Campinas, v. 13, n. 3, p. 131-145, jul./set. 2015.

ISSN: 1983-9030 
quando útil, é preservada, de Seleção Natural, a fim de acentuar sua relação com o poder humano de seleção. Mas a expressão muitas vezes usada pelo Sr. Herbert Spencer, de Sobrevivência do mais Apto, é mais exata e, às vezes, mais conveniente.

Desta forma, a análise que Darwin faz da natureza e da sociedade parte de pressupostos teóricos de autores que se esforçaram para legitimar formas concretas de competição, ligadas ao liberalismo econômico, vigente na época, assim como à prática do colonialismo.

Após a indicação de fontes das quais Darwin partiu para a elaboração de sua teoria evolucionista, procede-se com a exposição das formas sociais de competição e cooperação defendidas pelo próprio autor.

\section{AS IDEIAS DE DARWIN}

Primeiramente, serão enfatizadas as formas sociais de cooperação que aparecem no pensamento de Darwin, e que, possivelmente, levariam à interpretação feita pelos autores que estudam os Jogos Cooperativos, anteriormente citados. Simultaneamente, e, inevitavelmente, serão abordadas formas sociais de competição que o autor defende, visto que a cooperação, para Darwin, é importante, sobretudo, por ser útil, fortalecendo um determinado grupo para alguma competição relacionada à lei da seleção natural.

Um dos momentos em que Darwin defende formas de cooperação social, que consta de seu $A$ origem do homem refere-se às especulações do autor quanto à descendência do homem. $\mathrm{O}$ autor afirma que, por menos forte ou veloz que fosse, em relação a muitos outros animais, o homem conseguiu se sobressair e tornar-se superior a eles, em primeiro lugar, pelo seu desenvolvimento intelectual e, em segundo lugar, "pelas suas qualidades sociais que o levaram a prestar ajuda aos seus companheiros ou a deles recebê-la". 11:81

Para Darwin, há um "instinto social", 11:130 que foi mantido ao longo da descendência do homem pelo processo de seleção natural, anteriormente descrito. $\mathrm{Na}$ luta pela existência, a associação em grupo teria sido vantajosa a determinados indivíduos que, ao compartilhar o referido instinto, sobreviveram e tiveram descendentes.

Conexões: revista da Faculdade de Educação Física da UNICAMP, Campinas, v. 13, n. 3, p. 131-145, jul./set. 2015. ISSN: 1983-9030 
É importante lembrar que Darwin, no que se refere à hereditariedade, não divergia do francês Jean-Baptiste Lamarck (1744-1829), que defendia a existência da transmissão de caracteres adquiridos por uma geração a outra. Como notou Marco: "O que Darwin criticava em Lamarck não era sua concepção de hereditariedade, mas sim a importância que a vontade própria dos animais tinha sobre as mudanças orgânicas". ${ }^{12: 21}$ Darwin defendia que era o hábito, ao qual, muitas vezes o homem e os demais animais eram forçados - como no caso dos animais domesticados -, e não a vontade própria que determinava mudanças nos organismos.

No homem, o instinto social também é reforçado pelo hábito. Nossas ações, segundo Darwin, ${ }^{11}$ são determinadas, sobretudo, pelos desejos expressos e pelos juízos de nossos semelhantes; por exemplo, "o amor, a simpatia e o autocontrole são reforçados pelo hábito". 11:134

Além da cooperação entre indivíduos da mesma espécie contra indivíduos de outras espécies, ou para a manutenção da harmonia social, Darwin ${ }^{11}$ também descreve a importante cooperação entre indivíduos de um grupo, como uma tribo, para competir, lutar, contra os de outro grupo, mesmo que da mesma espécie. Para o autor, esta competição não representa uma objeção do selvagem à sociedade, devendo-se ao fato de que "os instintos sociais nunca se estendem a todos os indivíduos da mesma espécie". ${ }^{11: 13}$ Assim, estaria explicada a luta entre tribos ou entre classes sociais, não obstante o chamado instinto social.

Um aspecto da cooperação entre indivíduos da mesma espécie para a harmonia social, que não foi dito acima, diz respeito aos sacrifícios que cada um teria que fazer em nome da preservação da sociedade. Darwin, ao lembrar os casos de sentimento de ódio entre parentes próximos - como as abelhas operárias que matam o seu irmão zangão, assim como as abelhas rainhas que matam as suas irmãs rainhas -, afirma que são, provavelmente, produtos da seleção natural, e os explica dizendo que nestes casos "o desejo de matar os parentes mais próximos tem sido útil à comunidade". ${ }^{11: 130}$

Conexões: revista da Faculdade de Educação Física da UNICAMP, Campinas, v. 13, n. 3, p. 131-145, jul./set. 2015. ISSN: 1983-9030 
A questão torna-se problemática porque esta análise, de certa forma, é estendida aos comportamentos sociais, visto que o homem não escapa à lei da seleção natural. Nas palavras de Darwin ${ }^{11: 160}$ :

Uma tribo que conta com alguns membros que, possuindo em medida elevada o espírito de patriotismo, fidelidade, obediência, coragem e simpatia, estão sempre dispostos a ajudar-se um ao outro e a sacrificar-se em prol do bem-comum, poderia sair vitoriosa sobre algumas outras tribos: isto não seria nada mais e nada menos do que seleção natural.

O que há em comum entre as abelhas e os humanos, para Darwin, é que a sociedade torna-se um sujeito acima dos indivíduos, o único que realmente importa. A morte de muitos de seus membros, que serão os mais fracos da espécie, é plenamente justificada pela lei universal da seleção natural. Está, inclusive, legitimada a dominação de uma tribo por outra. No evolucionismo de Darwin, os indivíduos devem ser submissos ao todo que a sociedade representa; são como células de um tecido social, tal é o "coletivismo" darwinista.

Como já foi dito acima, a cooperação no pensamento evolucionista de Darwin cumpre o papel de fortalecer um grupo para competir, o que é necessário pela Lei da Seleção Natural. Este já é um aspecto que escapa à interpretação do darwinismo feita pelos autores que estudam os Jogos Cooperativos, citados anteriormente.

Agora, serão analisadas as ideias de Darwin sobre as formas de dominação social e sua possível legitimação pela Lei da Seleção Natural, o que nos leva a uma retomada da adoção dessas pelos estudiosos dos Jogos Cooperativos.

O exemplo da luta entre tribos já mostrou que Darwin estende implicações da Lei da Seleção Natural ao homem. Deixando clara a influência de Malthus em sua teoria, Darwin também se mostra contrário às formas sociais de ajuda aos mais necessitados, pois contribuem para o aumento de indivíduos fracos. Esta impressionante ideia está exposta no seguinte trecho:

Nos selvagens, as fraquezas do corpo e da mente são imediatamente eliminadas; aqueles que sobrevivem, apresentam normalmente um vigoroso estado de saúde. Nós, homens civilizados, por outro lado, envidamos todos os esforços para deter o processo de eliminação; construímos asilos para loucos, aleijados e doentes; instituímos leis para os pobres e os nossos médicos exercitam ao máximo a sua habilidade para salvar a vida de quem quer que seja no último momento. Há motivo para se crer que a vacinação tenha salvo

Conexões: revista da Faculdade de Educação Física da UNICAMP, Campinas, v. 13, n. 3, p. 131-145, jul./set. 2015. ISSN: 1983-9030 
um grande número daqueles que, por sua débil constituição física, não teriam em tempo resistido à varíola. Desta maneira, os membros fracos das sociedades civilizadas propagam o seu gênero. Nenhum daqueles que se têm dedicado à criação dos animais domésticos duvidará que isto pode ser altamente perigoso para a raça humana. ${ }^{11: 161-162}$

Ajudar os mais "fracos" constitui, para Darwin, um perigo para a raça humana. Ele, assim como Malthus, defende a livre-concorrência como forma de se beneficiar os mais "capazes". Darwin admite que um acúmulo de riquezas herdado, em certa medida, pode favorecer um indivíduo, de modo que "os filhos dos ricos levam vantagem sobre aqueles dos pobres na corrida para o êxito, independentemente da superioridade física ou mental". 11:163

Entretanto, para o autor, como as leis do mercado exigem alto grau de luta, o sucesso dos mais aptos está garantido, apesar de certa interferência da riqueza herdada. Homens ricos que se tornam ociosos podem vir a perder sua fortuna; daí decorre a conclusão de que "nem mesmo uma moderada acumulação de riqueza interfere no processo de seleção". 11:163

Desta forma, Darwin ${ }^{11: 163}$ defende a propriedade privada, mesmo que herdada; e, sobre a legitimação do colonialismo, o pensamento do autor torna-se claro quando afirma que:

[...] a hereditariedade da propriedade, em si mesma está muito longe de constituir um perigo; com efeito, sem acumulação de capital as artes não poderiam progredir e é, sobretudo, mediante o seu poder que as raças civilizadas estenderam e continuam estendendo por toda parte a sua ordem, de modo a assumir o lugar das raças inferiores.

Através da seleção natural, Darwin tenta legitimar a dominação britânica e o aniquilamento dos povos selvagens, das raças "inferiores". Quando o autor fala dos "notáveis êxitos dos ingleses como colonizadores", ${ }^{11: 170}$ ele recorre à seleção natural. Quando analisa a existência de terras férteis, que poderiam sustentar numerosas famílias, mas que são povoadas apenas por poucos nativos errantes, ele deduz que "a luta pela existência não tem sido suficientemente dura para forçar o homem a atingir o seu mais elevado nível”. ${ }^{11: 171}$

Para finalizar a apresentação das ideias de Darwin, um trecho decisivo para se entender a importância que o autor confere à competição na sociedade, em que novamente está presente a influência do pensamento de Malthus ${ }^{11: 711}$, é o seguinte:

Conexões: revista da Faculdade de Educação Física da UNICAMP, Campinas, v. 13, n. 3, p. 131-145, jul./set. 2015. ISSN: 1983-9030 
[...] todos aqueles que não podem evitar a pobreza para os próprios filhos deveriam evitar o matrimônio; na verdade, a pobreza não só representa um grande mal, mas tende ao próprio incremento, levando à desconsideração do matrimônio. Por outro lado, Galton observou que, se o prudente evita o matrimônio enquanto que o incauto se casa, os membros inferiores tendem a suplantar os membros melhores da sociedade. Como qualquer outro animal, o homem sem dúvida chegou à sua atual condição elevada através de uma luta pela existência, devida ao seu rápido progresso; se deve progredir ainda mais, teme-se que deva estar sujeito a uma dura batalha. Se assim não fosse, chafurdaria na indolência e os mais dotados não teriam mais êxito na luta pela vida do que os menos dotados. Por isso, a nossa natural taxa de aumento, embora leve a muitos prejuízos óbvios, não deve ser de algum modo muito reduzida. Deveria estar aberta a competição para todos os homens; e com as leis e os costumes não se deveria impedir que os mais capazes tivessem melhor êxito e que criassem o maior número de filhos.

O que Darwin defende como fundamental para o progresso da humanidade é a competição aberta a todos, para que os indivíduos mais "aptos" sejam selecionados, transmitindo seus caracteres de geração em geração. Para ele, os indivíduos mais "fracos" devem ser eliminados, devido à inelutável lei da seleção natural, pelo bem da humanidade.

\section{CONSIDERAÇÕES FINAIS}

Em virtude da análise aqui empreendida, é possível relacionar o pensamento de Darwin com o liberalismo econômico e com a prática do colonialismo britânico. Com isto, após a exposição de pontos fundamentais das duas principais obras de Darwin, A origem das espécies e $A$ origem do homem, é possível afirmar que a interpretação do pensamento do autor feita pelos estudiosos dos Jogos Cooperativos, anteriormente citados, possui sérios problemas.

Talvez Darwin não tenha, realmente, ficado tão amargurado com o uso de sua teoria da seleção natural para a legitimação de desigualdades. O autor não deixa de defender a cooperação, mas, quando o faz, a considera um meio para fortalecer um grupo para determinadas formas de competição, ligadas à seleção natural, que implicam em dominação, espoliação e, inclusive, em aniquilamento.

O presente trabalho tentou indicar problemas e limitações na interpretação do darwinismo feita por Orlick ${ }^{1}$ e os autores que o adotam, que apontaria Darwin como um grande defensor de formas sociais de cooperação, o que não parece ser fiel ao seu pensamento.

Conexões: revista da Faculdade de Educação Física da UNICAMP, Campinas, v. 13, n. 3, p. 131-145, jul./set. 2015. ISSN: 1983-9030 
Isto não significa de forma alguma desqualificar qualquer um dos autores citados no presente trabalho, mas somente frisar que é necessário buscar outras referências que combatam as formas sociais de competição ligadas especificamente à dominação, para que o tão importante estudo dos Jogos Cooperativos possa continuar mostrando como é possível e necessário que nós alcancemos uma sociedade mais justa, igualitária e em que possam florescer, cada vez mais, novas formas de cooperação.

\section{REFERÊNCIAS}

${ }^{1}$ ORLICK, T. Vencendo a competição. São Paulo: Círculo do Livro, 1989.

${ }^{2}$ BROTTO, F. O. Jogos cooperativos: se o importante é competir, o fundamental é cooperar. Santos: Renovada, 1997.

${ }^{3}$ BROTTO, F. O. Jogos cooperativos: o jogo e o esporte como um exercício de convivência. Santos: Projeto Cooperação, 2001.

${ }^{4}$ BROWN, G. Jogos cooperativos: teoria e prática. 5. ed. São Leopoldo: Sinodal, 2004.

${ }^{5}$ SOLER, R. Jogos cooperativos para educação infantil. Rio de Janeiro: Sprint, 2003.

${ }^{6}$ SOLER, R. Jogos cooperativos. 2. ed. Rio de Janeiro: Sprint, 2003.

${ }^{7}$ HOBSBAWM, E. J. A era das revoluções: 1789-1848. 7. ed. Rio de Janeiro: Paz e Terra, 1989.

${ }^{8}$ MALTHUS, T. R. Ensaio sobre o princípio da população. Lisboa: Europa-América, 1798.

${ }^{9}$ DARWIN, C. A origem das espécies: ilustrada. São Paulo: Melhoramentos, 1982.

Conexões: revista da Faculdade de Educação Física da UNICAMP, Campinas, v. 13, n. 3, p. 131-145, jul./set. 2015. ISSN: 1983-9030 
${ }^{10}$ SPENCER, H. Do progresso: sua lei e sua causa. Lisboa: Editorial Inquérito, 1939.

${ }^{11}$ DARWIN, C. A origem do homem. In: A origem do homem e a seleção sexual.

São Paulo: Hemus, 1974.

${ }^{12}$ MARCO, N. O que é darwinismo. 2. ed. São Paulo: Brasiliense, 1989.

Recebido em: 06 nov. 2014

Aceito em: 19 abr. 2015

Contato: jiliraneto@gmaol.com

Conexões: revista da Faculdade de Educação Física da UNICAMP, Campinas, v. 13, n. 3, p. 131-145, jul./set. 2015. ISSN: 1983-9030 